\title{
Stress distribution analysis on the one-stage non-submerged and two-stage submerged system implant supported bridge
}

\author{
Joko Prihatono*, Taufik Sumarsongko**, Tata Cipta Dirgantara***, Rasmi Rikmasari** \\ *Prosthodontics Clinic of Pertamina Jaya Hospital, Indonesia \\ **Department of Prosthodontics Faculty of Dentistry Universitas Padjadjaran, Indonesia \\ ***Department of Light Weight Structures Faculty of Mechanical and Aerospace Engineering \\ Bandung Institute of Technology, Indonesia
}

\begin{abstract}
Introduction: Tooth restoration and implant-supported was one of the methods to overcome the free end cases. Abutment and implant are two components that are fused together by a screw. Therefore, the main problem to solve are loosened screw and implant or abutment fracture because of increasing unpredictable potential force on the implant, abutment, and screw. The purpose of this research was to describe the distribution stress between the connection of the body of implant and abutment on the submerged and non-submerged design of the implant supported bridge. Methods: The submerged and non-submerged design implant have been analyzed using the Finite Element Method under lateral and vertical static load for $180 \mathrm{~N}$. The numeric model for lower jaw posterior segmented bone was determined by computed tomography, and the load measurement was performed to observe the distribution at the connection between the body of implant and the abutment of the implant supported bridge submerge and non-submerged design. Result: At the lateral load, the distribution strength value was $1.562 \times 10^{7} \mathrm{~Pa}$, whilst for the non-submerged was $9.63 \times 10^{7} \mathrm{~Pa}$. At the vertical load, the distribution strength value was $1.038 \times 10^{7} \mathrm{~Pa}$, whilst for the non-submerged was $3.342 \times 10^{7} \mathrm{~Pa}$. At the load of $180 \mathrm{~N}$ towards the vertical and lateral on the supported implant bridge, the distribution strength value had a smaller scale compared to the ultimate tensile strength (UTS), which was $1040 \mathrm{MPa}\left(1.04 \times 10^{9} \mathrm{~Pa}\right)$. Conclusion: Both of the design including the secondary component (abutment) was safe to used as the supporting implant bridge.
\end{abstract}

Keywords: Distribution strength, mastication load, submerged and non-submerged implant design

P-ISSN 1979-0201, e-ISSN 2549-6212 Available from:http://jurnal.unpad.ac.id/pjd/article/view/16233

DOI:10.24198/pjd.vol30no1.16233

Submission: Dec 2017 Publishing: Mar 2018

\section{INTRODUCTION}

Successful dental implants in edentulous patients, making implant treatment are also used in partial tooth loss patients. ${ }^{1}$ Implant failure usually occurs in the area between crown and abutment or between abutments and implants due to fracture or looseness of screw and implant or abutment fracture due to increased potential style on the implant, abutment, and screw that can not be

Corresponding author: Joko Prihatono, Prosthodontics Clinic of Pertamina Jaya Hospital, Indonesia Jl. Pandawa Blok A-1 No. 14 \& 15 Bantar Jati II Bumi Indah Prastal, Bogor Utara Telp. (0251) 8363990. 
predicted. ${ }^{2,3}$ The technique of mounting dental implants in the posterior region, a non-submerged one stage surgical procedure positioned the transition between the shoulder of the implant and the secondary component at the mucosal level indicates a biomechanical advantage, which reduces the leverage effect and produces a bending moment working at the confluence of the implant and the superstructure. ${ }^{4,5}$

In a two-stage submerged implant placement technique, the entire length of the implant from apical to shoulder is inserted as deep as the top of the bone, and the inclusion of the secondary component is performed by opening the mucosal tissue or the second-stage operation. ${ }^{6,7}$ Given that the implants and abutments are essentially two components together by screw then this interface has gap approximately 10 micron. ${ }^{6,8}$

The maximum pressure area is numerically located in the neck of the implant, and the likelihood of overloading may occur due to vertical intrusion load. 2,8 Non-axial loads are often associated with marginal bone loss, osseointegrated failure, implant failure and prosthetic components, and cementation failure when combined with original teeth..$^{9-11}$

Two closely related factors in the crown and mechanical implant failure are an excessive tightening of the support screw causing crown failure in the design of internal-hex and externalhex connection implants, as well as excessive mastication loads being transferred from the occlusal plane to the pressure concentration on the surface between the support and body implant. ${ }^{9}$

\section{METHODS}

This research was conducted to analyse stress distribution to denture bridge support of nonsubmerged design implant with a submerged design using three-dimensional element finite element analysis. The research design was explorative research with the descriptive method using the numerical technique of finite element method. ${ }^{2}$

Materials and tools needed in this study were as follows: SSII Implant (brand Osstem ${ }^{\circledR}$ ) with size $4.8 \times 10 \mathrm{~mm}$; Implant 2 Drill (2D Implant Co., Ltd) with size $4.8 \times 10 \mathrm{~mm}$; 3D-Doctor software; Catia ${ }^{\circledR}$ software; Finite element software; and Skyscan ${ }^{\circledR}$ Microscanner brands and computer devices.

Steps of dental and implant modelling and the analysis of the three-dimensional element method were performed by first converting the CT-Scan image (Figure 1a) to the 3D-Cloud point model. Then change the 3D-Cloud point results (Figure 1b) to 3D-Solid by using the CATIA V5 program (Figure 1C). After that, making an implant model using Autodesk Inventor. Performed extrude process on a cross-cut transverse work plane to create a groove on the side of the abutment. Also extruded on the base to make a threaded connection on the implant. The thread was made by tapping process (Figure 2a). For the abutment of the submerged design implant, there was an extruding process on the inside and the manufacture of the outer portion of the hexagon shape (Figure 2b). The implant portion was performed using the same method as the abutment, but the thread was manually made using the trapezoidal shape (Figure $2 \mathrm{c}$ ). The final

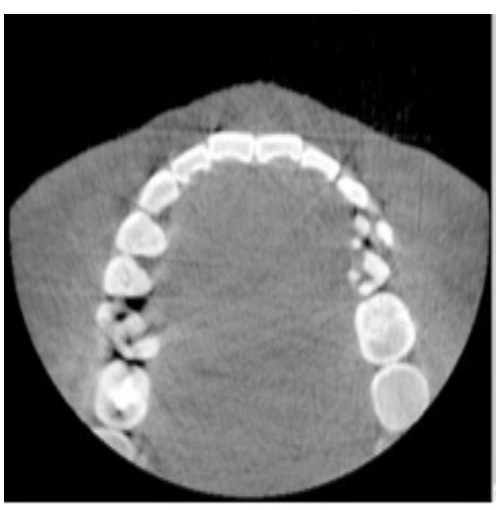

A

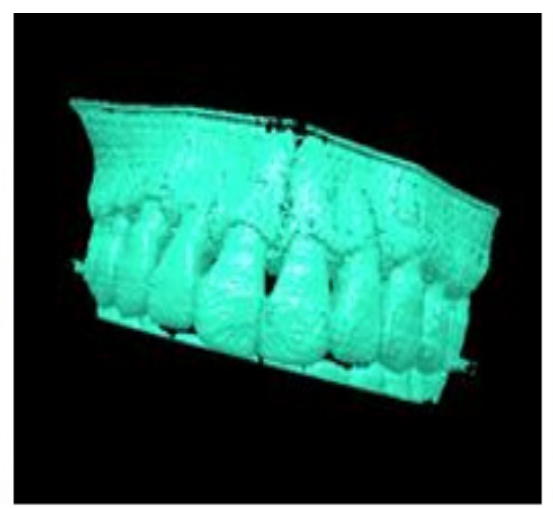

B

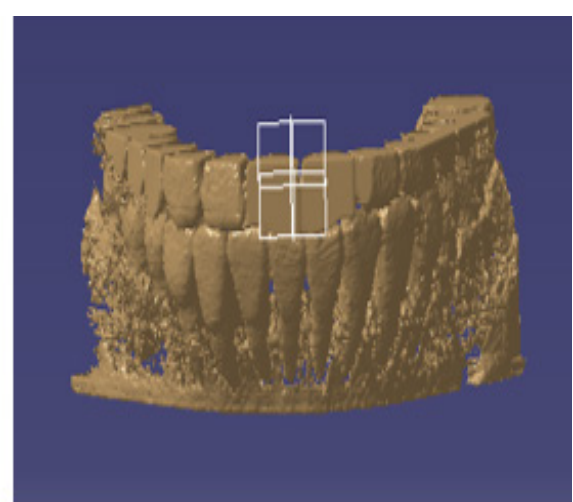

C

Figure 1. (a). CT Scan result; (b). 3D-Cloud point model; (c). 3D-Solid model 


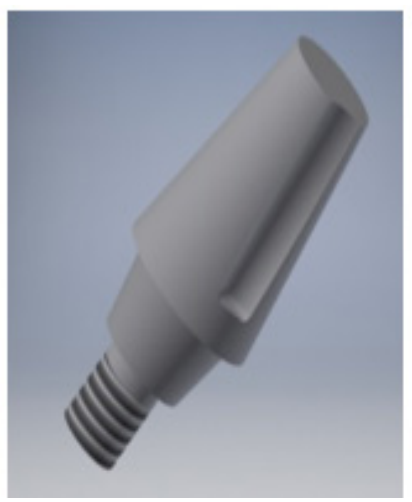

A

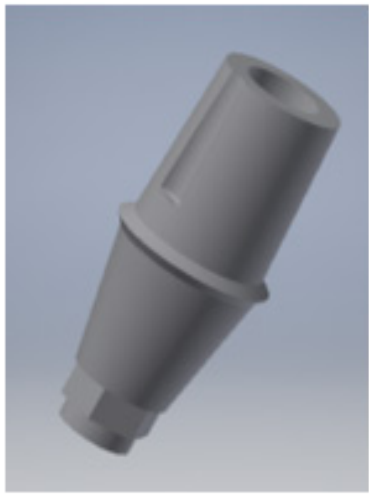

B

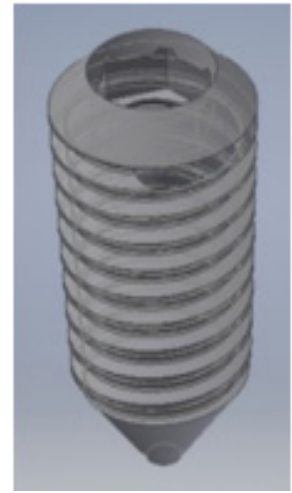

C

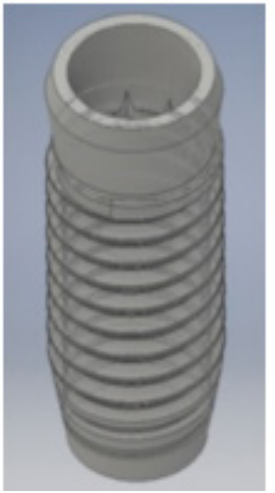

D

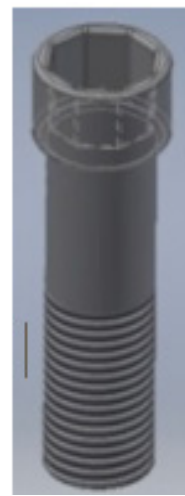

E

Figure 2. A. Non-submerged abutment; B. Submerged abutment; C. Non-submerged implant; D. Submerged implant; E. Internal implant connection

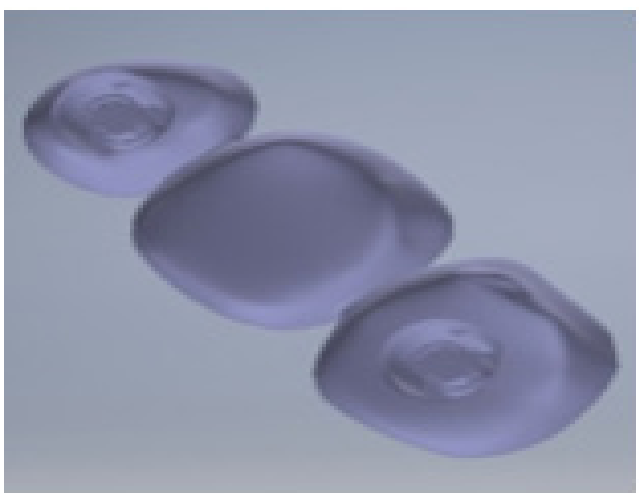

A

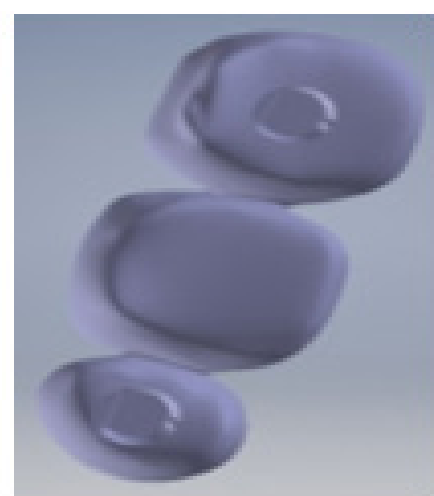

B

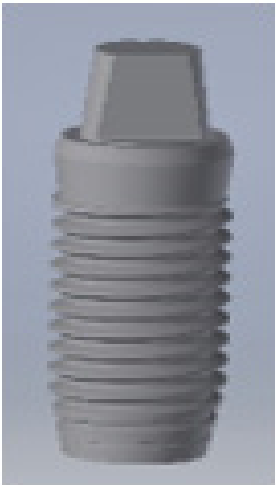

C

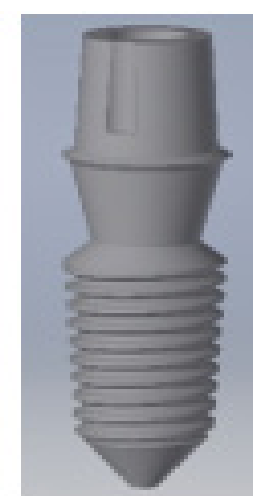

D

Figure 3. A. Submerged implant crown; B. Non-submerged implant crown; C. Submerged implant and abutment; D. Nonsubmerged implant and abutment

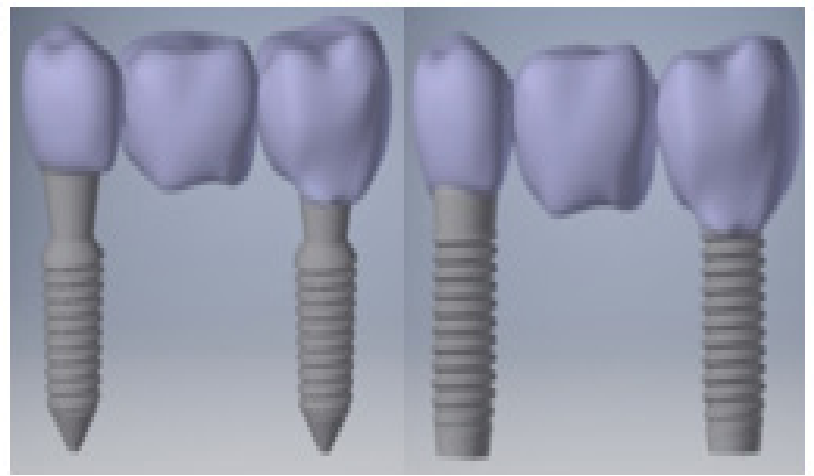

A

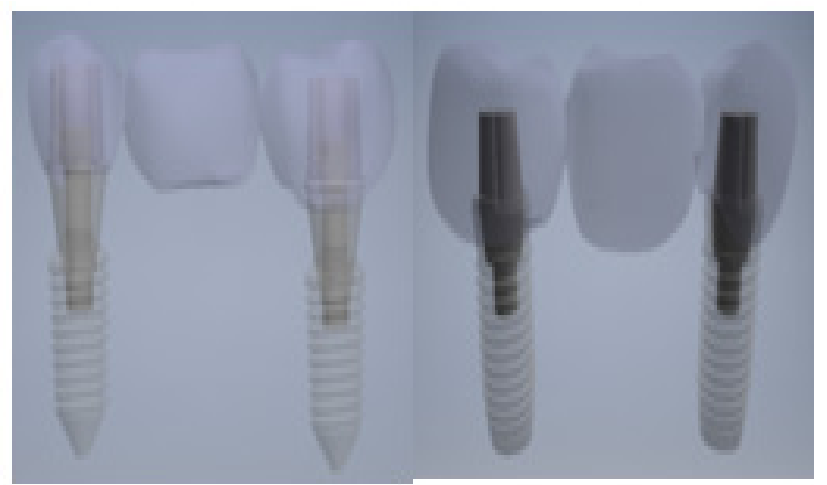

B

Figure 4. Crown implant join in (a) Submerged implant; and (b) Non-submerged implant

cutting results for the submerged implants were added the extruded hexagons according to the abutment form of the pair while for non-submerged implants only the abutment (Figure 2d). The internal connection was also made by using only the extrude and tapping process for the thread with an inner diameter bolt head (Figure 2e). The next step was to assemble all models using the Autodesk Inventor program. For the abutments combined with the teeth used combining process so that the crown can be obtained with a fitting hole in accordance with the abutment form. Figure $3 a$ and Figure $3 b$ show the crown with abutment holes after the combining process. For abutments and implants were used constraints on the axis and sides of each other, 


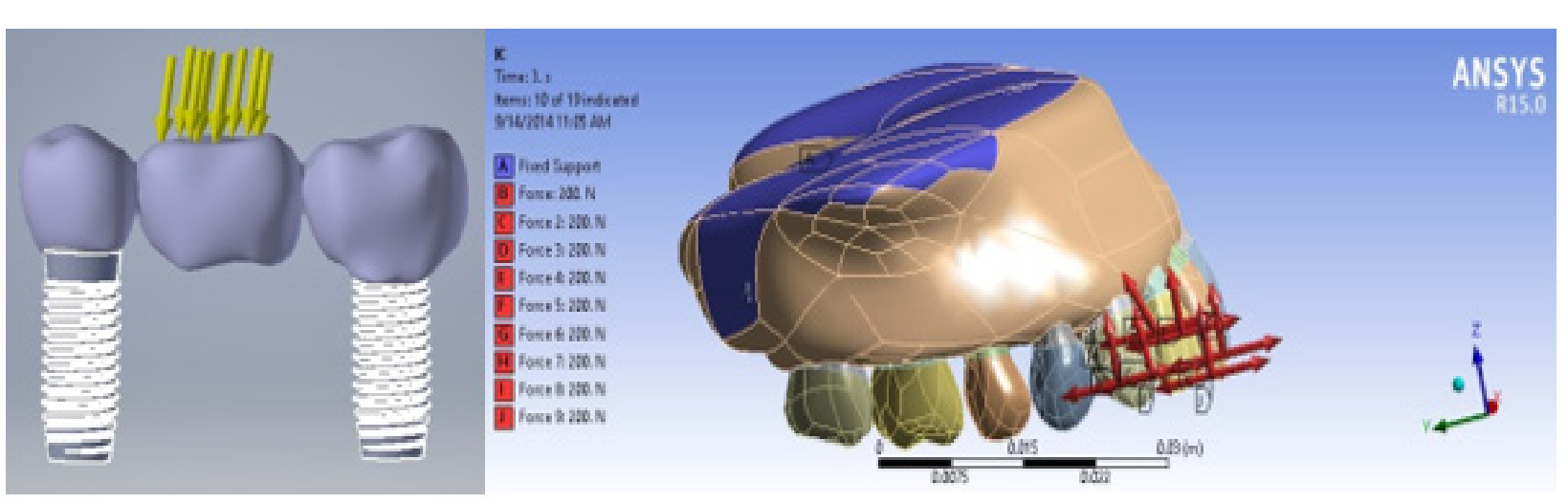

Figure 5a. Fixated implant (marked with white colour) to be loaded in the Autodesk program; and (5b) in the ANSYS program

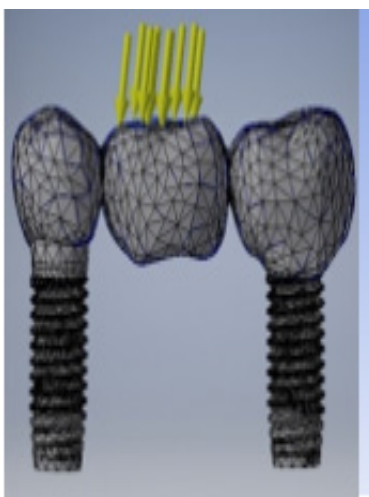

A

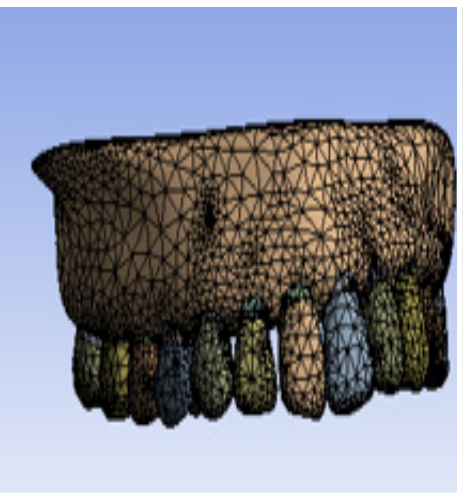

B

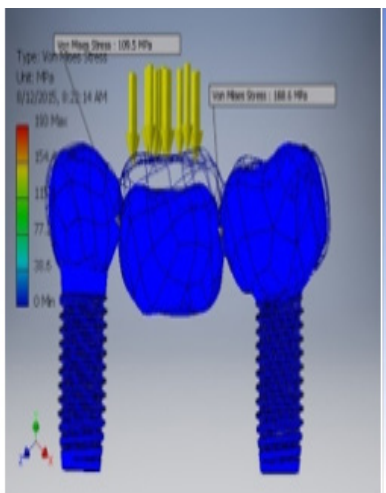

C

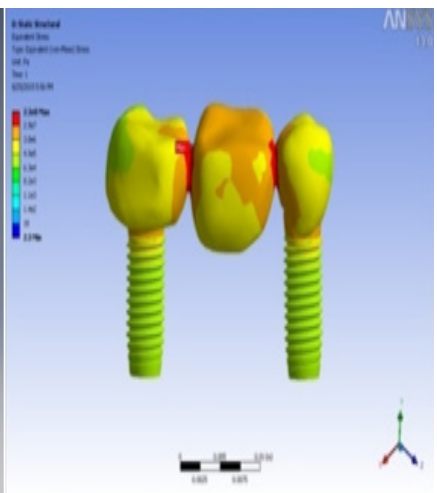

D

Figure 6. A. Meshing result in Autodesk program; B. Meshing result in ANSYS program; C. Final result of the stress value in Autodesk program; D. Final result of the stress value in ANSYS program

so that obtained the results as shown in Figure $3 c$ and Figure $3 \mathrm{~d}$. The crown and implant were also combined by constraining on the coinciding side (Figure 4).

Afterwards, a finite element analysis was performed using the ANSYS and Autodesk. Material data for each model section was included. In this study, the crown material used is porcelain-based Zirconia and implant using titanium alloy grade 23 material. Limits and loading to be done on the model were determined. In Figure 5, the load was indicated by the direction of the arrow and the restriction of fixation on the white portion. In the research, loading was performed on two kinds of vertical and lateral loading. The load given is $180 \mathrm{~N}$. Figure $5 \mathrm{a}$ was an example of loading on the Autodesk program, and the Figure $5 \mathrm{~b}$ was an example in the ANSYS program.

The meshing was performed after to obtained small elements as reference points of voltage distribution so that it can be analysed three-dimensional element method with the result of voltage distribution in the form of colour. Figure 6 shows an example of meshing results. The model was then run to obtain results such as shown in Figure 6a images on the Autodesk program and in Figure $6 \mathrm{~b}$ on the ANSYS program. The advantages of the ANSYS program are the scale of the results obtained can be converted into a logarithmic scale so that the spread of the stress concentration can be more easily seen (Figure $6 c$ and Figure $6 d$ ).

\section{RESULT}

The result of this research was the stress distribution pattern shown by the colour spectrum level along with the location of the voltage and the maximum value of the voltage occurring at that location. The lateral loading results with a $180 \mathrm{~N}$ load at an angle of $450^{\circ}$. In a non-submerged design implant accompanied by a crown showing a maximum voltage value of $2.3 \times 108 \mathrm{~Pa}$ was 

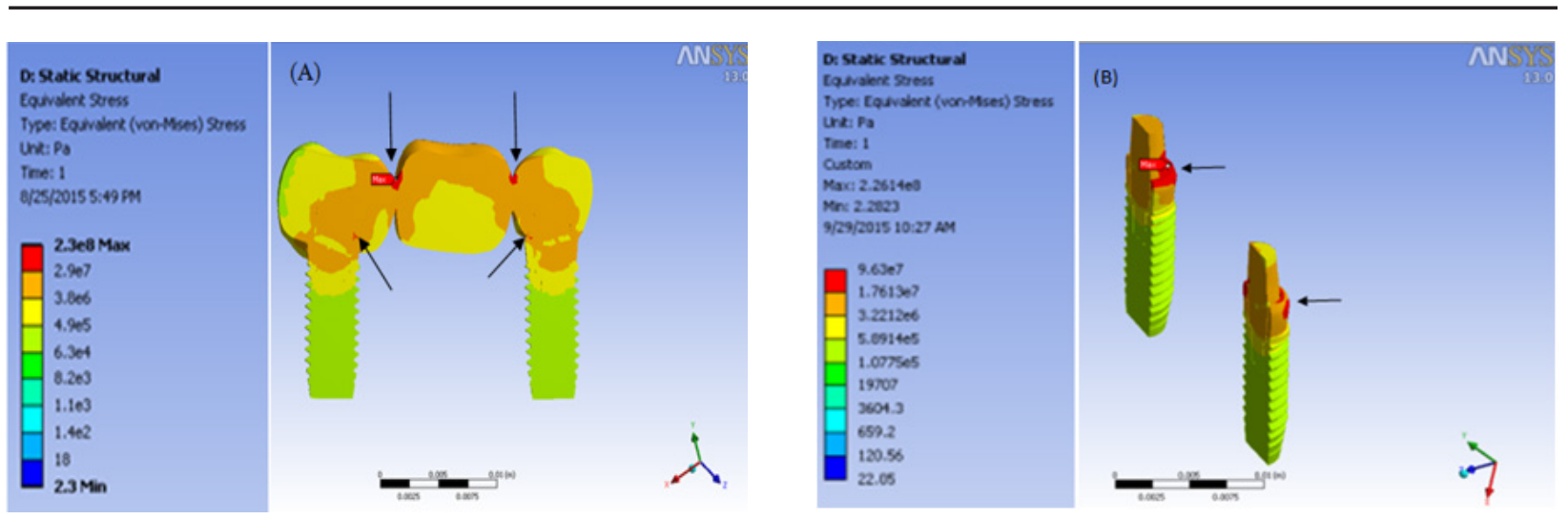

A
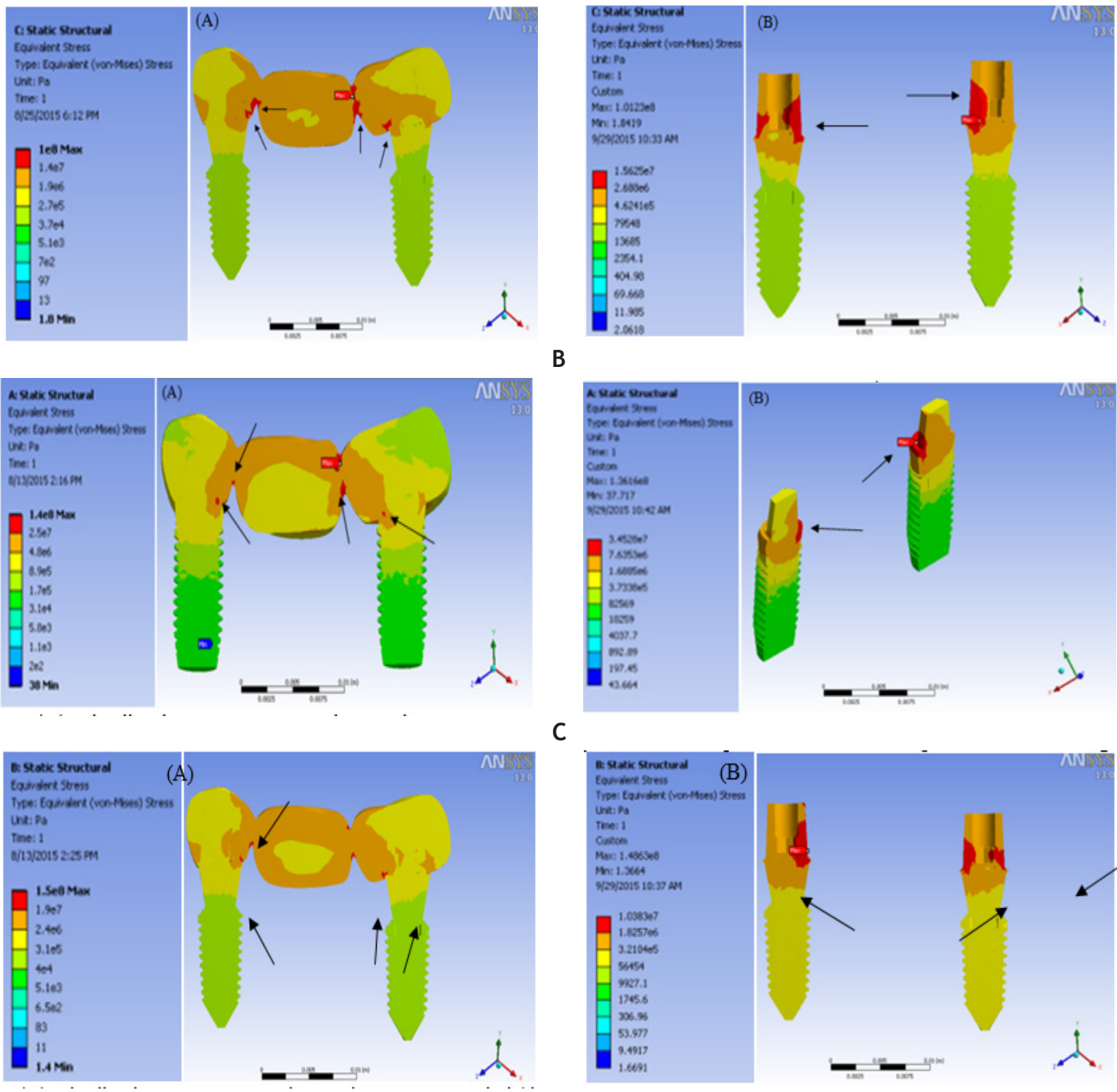

C
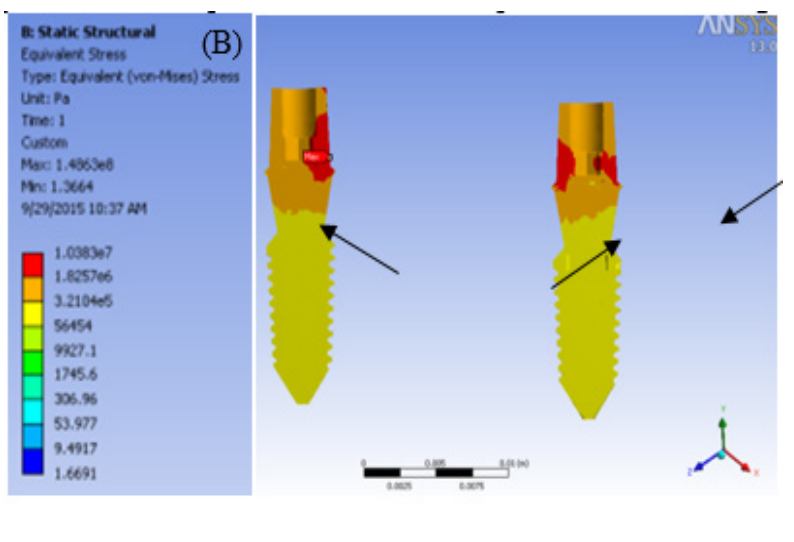

Figure 7. Von Mises stress distribution on the sagittal piece (in logarithmic scale) of non-submerged implants due to lateral loading (a); due to vertical loading (b) and submerged implants due to lateral loading (c); and due to vertical loading (d). Left: on the bridge; Right: on the connection between the implant and the abutment 
occurred at the junction between the crown and pontic, while the maximum voltage value in the area between the implant and the abutment is $9.63 \times 107 \mathrm{~Pa}$ (Figure 7a). The result of vertical implant loading of the non-submerged design with the crown indicated that the maximum stress value of $1.4 \times 108 \mathrm{~Pa}$ occurs at the connection portion between the crown and pontic, while the maximal voltage value in the area between implant and abutment is $3.452 \times 107 \mathrm{~Pa}$ (Figure 7b). The lateral loading of the submerged design implant with the crown indicated that the maximum stress value of $1 \times 108 \mathrm{~Pa}$ was occurred at the junction between the crown and pontic, while the maximal stress value between the implant and abutment area is $1.562 \times 107 \mathrm{~Pa}$ (Figure 7c). The result of vertical loading of the submerged design implant with crown indicated that the maximum stress value of $1.4 \times 108 \mathrm{~Pa}$ was occurred at the connection portion between the crown and pontic, while the maximal voltage value in the connection between the implant and abutment was $1.038 \times 107 \mathrm{~Pa}$ (Figure 7d).

\section{DISCUSSION}

In the lateral loading of denture bridges of nonsubmerged design support implants, the maximal stress value between the implant and abutment areas was found at $9.63 \times 107 \mathrm{~Pa}$, whereas in vertical loading the maximum voltage value in the interline between the implant and the abutment was $3.452 \times 107 \mathrm{~Pa}$. In the lateral loading of denture bridges the support of the submerged design implants, the maximal stress value between the implant and abutment areas is $1.562 \times 107 \mathrm{~Pa}$, whereas in vertical loading the maximum voltage value in the area between the implant and the abutment was $1.038 \times 107 \mathrm{~Pa}$.

If a material gets a voltage exceeding yield (threshold), then it undergoes plastic deformation until the material is broken or damaged. This situation is called Tensile Strength Ultimate (UTS). ${ }^{3,12}$ In the vertical or lateral load of $180 \mathrm{~N}$, the stress distribution in the connection region between the implant and the abutment of the submerged design and the non-submerged design is less than the ultimate tensile strength value of
$1040 \mathrm{MPa}(1.04 \times 109 \mathrm{~Pa})$, so both types of implant design and its secondary components (abutment) are safe to use for dental bridge support.

Distribution of tension in the connection area between the implant and the abutment of the submerged and non-submerged design on the 180 $\mathrm{N}$ load of the vertical direction was less than the lateral loading due to the vertical force loading force held by the resultant mass of the length and length of the implant diameter, whereas in lateral force loading only retained by the resultant not as long as the size of the implant, but only held in the shoulder part of the implant and part of the implanted body in the direction of the $450^{\circ}$ angle to the lateral and apical direction.

Based on a study conducted by Larson ${ }^{10}$, the normal force of mastication movement was in the range of 9-180 Newton while the maximum force due to bruxism in men was $911 \mathrm{~N}$ in molar teeth and $569 \mathrm{~N}$ in incisors. The occlusal power above the implant must be controlled to prevent eccentric contact with the parafunctional movement since such forces can damage the bone around the implant. ${ }^{10,13}$

To reduce the load received by the implant body as a result of the pressure received can be achieved by increasing the number of implants ${ }^{14}$, using a large implant diameter ${ }^{15}$, reducing the occlusal plane of the tooth, using a smaller occlusal angle, for example $100^{\circ}$ so that the force implanted to the surface of the implant is smaller when using a $300^{\circ}$ occlusal angle.

The direction of pressure on the prosthesis results in variations in the distribution of stresses in the implanted body. The pressure that leads to the ridge of the denture crown causes the pressure to be concentrated at the tip of the implant on the same side and the neck of the implant on the opposite side. Pressure centred on the implant neck will lead to bone resorption in the area. Bone resorption in the neck region of the implant is the beginning of serious damage. The safe voltage distributed evenly throughout the body of the implant is a voltage parallel to the implant body which can be obtained by placing the implant perpendicular to the occlusion plane.

The placement of two or three implants in the case of free-tooth loss is highly advantageous 
for supporting a bridge denture. According to Block, if the implant is used short with a long bridge, it is recommended to use one implant holding a single restoration. Desai and Karthikeyan ${ }^{16}$ suggest that if there is a mesio-distal space of more than 12.5 $\mathrm{mm}$, then to withstand the chewing force the use of double implants as support is more advisable. ${ }^{17}$

Research conducted by Bidez and Misch ${ }^{14}$ shows that the distribution of stress is more even and localised to the buffer bone tissue between the use of three implants compared with only two implants in the case of premolar one, premolar two, and one lower molar. This is also in accordance with the opinion of Hobkirt et al. ${ }^{14}$ recommended the use of one implant to replace one missing tooth in the posterior region.

On the other hand, Misch ${ }^{18}$ said overall the most effective way to overcome the excessive load of dental implants is to increase the number of implants used as a support to the existing superstructure. On the other hand, Misch18 also says that the bridge construction as a superstructure on the loss of three posterior teeth can be done on condition that the patient has a low or unbearable chewing pressure, and has a healthy and healthy buffer bone tissue..$^{14,15}$ In another study conducted by Nang Pow et al. ${ }^{15}$ showed the occurrence of implant fracture after implantation for 5 years, ie for single restoration users of $0.1 \%$ and bridges of $0.4 \% . .^{15}$ Likewise research conducted by Goodace reported implant failure in single restoration users of $3 \%$ and bridges on the mandible by $6 \% .{ }^{17}$

In non-submerged system implants, the implant is placed in one stage of surgery. The implant body is a straight cylindrical shape with a triangular screw and an internal link between an octagonal or octagonal shaped implant and abutment with a morse taper concept that provides excellent stabilisation in the connection area. The connection with the superstructure is located within the body of the implant which will remove micro wobbles and prevent bone resorption. This exceptional configuration ensures precision and avoidance of both parts so loosely as the typical surface area, and corner of $80^{\circ}$ produce mechanically locking friction fit and have micro gap less than 10 microns. This concept is supported by the fact that the strength of loosening torque is $7-24 \%$ greater than the tightening torque time, whereas if by screw design, to open the screw it only takes $10 \%$ less power than the strength of the fastening time and compared to standard screws, these connections can withstand torques 4 times greater than can be withheld by standard connections. The function of the morse taper abutment connection is to remove the load on the thread of the abutment. ${ }^{4,6,19}$

In submerged implants connected to abutments, bone crystals and soft tissue dimensions around the implant will be affected. While in non-submerged implants usually wear a one-piece implant, or an implant extending over the alveolar peak, so that the height of the marginal bone remains normal.

Voltage distribution across multiple implants or splints reduces the tension on the implant body thereby reducing the risk of marginal bone revulsion and fracture implants along with other implant components. Sullivan reported that a single implant placement with a diameter of $4 \mathrm{~mm}$ in the molar region had a fracture risk of $14 \%$ when compared with some implants combined with a $1 \%$ fracture risk. The splinted implant reduced the risk of a loose screw. Balshi reported that single implant placement in the molar region had a $48 \%$ lethal screw risk after three years. When two implants in the molar region were splinted together, the incident of screw loosen decreases $8 \%$ at the same time. ${ }^{20,21}$

Based on the analysis of the three-dimensional element method of stress distribution occurring at the connection between the implant and the abutment on the denture bridge the implant support of the submerged and non-submerged systems has similar patterns and distribution locations. The value of stress distribution at the connection between the implant and the abutment with vertical and lateral loading with a static load of $180 \mathrm{~N}$ on the submerged and non-submerged submerged surge support bridge is still smaller than the ultimate tensile strength material value. This suggested that denture proprietary bridge support of submerged and non-submerged design implants is still relatively safe to use in cases of loss of three posterior teeth. The voltage distribution 
values of vertical and lateral loading with static loads of $180 \mathrm{~N}$ at the bridge dent bridge junction are still greater than the tension in the connection between the implant and the abutment on the submerged and non-submerged design implants.

\section{CONCLUSION}

Both submerged and non-submerged implants, including the secondary component (abutment) was safe to used as the supporting implant bridge in three posterior tooth loss case.

\section{REFERENCES}

1. Newman MG, Takei HH, Klokkevold PR, Carranza FA. Carranza's clinical periodontology. $11^{\text {th }} \mathrm{ed}$. St. Louis: Elsevier; 2012. p. 635-48.

2. Segundo RMH, Oshima HMS, Silva INL, Junior LHB, Mota EG, Coelho LFB. Stress distribution on external hexagon implant system using $3 \mathrm{D}$ finite element analysis. Acta Odontol Latinoam 2007;20(2):79-81.

3. Taylor TD, Agar JA, Vogiatzi T. Implant prosthodontics: current perspective and future directions. Int J Oral and Maxillofacial Implants 2000;15(1):66-75.

4. Buser D, Bernard JP. Implants in the load carrying part of the dentition, In: Lee $D$. Research on the clinical result of Koreas Avana implant. J Korean Dent Ass 2000:38(6):946-75.

5. Tedyasihto B. Buku ajar implantologi mulut teori dan praktek. Jakarta: EGC; 2010. p. 3351, 58, 78-82.

6. Hidayat $\mathrm{H}$. Getting started in dental implant. Jakarta: Voxa; 2003. p. 2-13, 17-23.

7. Drago C. Implant restorations: A step-by-step guide. $2^{\text {nd }}$ ed. Blackwell Munksgaard; 2007. p. 79-80.

8. Baggi L, Cappelloni I, Girolamo MD, Maceri F, Vairo G. The influence of implant diameter and length on stress distribution of osseointegrated implants related to crestal bone geometry: A three-dimensional finite element analysis. J Prosthet Dent 2008;100:422-31. DOI: 10.1016/ S0022-3913(08)60259-0

9. Van Staden RC, Guan H, Loo YC, Johnson
NW, Meredith N. Comparative analysis of two implant crown connection systems; A finite element study. Applied Osseointegration Res 2008;6:48-53.

10. Larson TD. The effect to occlusal forces on restorations. J Minnesota Dent Assoc 2012;Nov-Des:25-6.

11. Seth S, Kalra P. Effect of dental implant parameters on stress distribution at boneimplant interface. Int JSci Res 2013;2(6):121-4.

12. Hibbeler RC. Mechanical of material. $8^{\text {th }}$ ed. Boston, USA; Pearson Prentice Hall; 2011. p. 84-7.

13. Sener I, Aslan MA, Bereket C. The effect of implant therapy on maximum bite force in edentulous elderly patients: An in vivo study. Turkish J Geriatrics 2015;18(1):75-80.

14. Hobkirt JA. Watson RM, Searson LJJ. Introducing dental implant. Edinburg: Churchill Livingstone; 2003. p. 86, 88.

15. Pow EHN, Leung KCM. Prosthodontic complications in dental implant therapy. Hong Kong Dent J 2008;5(2):1-7.

16. Desai SR, Karthikeyan I, Singh R. Evaluation of micromovements and stresses around single wide diameter and double implants for replacing mandibular molar: A three dimensional FEA. ISRN Dent. 2012;2012:1-10. DOI: $10.5402 / 2012 / 680587$

17. Rais SW. Analisis distribusi tegangan pada tulang alveolar dari implan gigi dengan restorasi tunggal dan jembatan menggunakan metode elemen hingga tiga dimensi [minor thesis]. Bandung: Unpad; 2013. p. 2-4,8,21-2.

18. Misch CE. Dental implant prosthetics. St. Louis: Mosby, Inc: 2005. p. 83, 305-6.

19. Choi K. Osstem implants system. $2^{\text {nd }}$ ed. Seoul, Korea: Osstem implants Co.; 2013. p. 26-30.

20. Misch CE. Contemporary implant dentistry. $3^{\text {rd }}$ ed. Canada: Mosby, Inc; 2008. p. 31,86,94, 106,544-5

21. Nissan J, Ghelfan O, Gross M, Chaushu G. Analysis of load transfer and stress distribution by splinted and unsplinted implant-supported fixed cemented restorations. J Oral Rehabil 2010;37:658-62. DOI: $10.1111 / j .1365-$ 2842.2010.02096.x 